\title{
The Effect of Different Fly Ash and Vanadium Carbide Contents on the Various Properties of Hypereutectic Al-si Alloys-Based Hybrid Nanocomposites
}

\author{
Waheed AbuShanab \\ King Abdulaziz University \\ Essam Moustafa \\ King Abdulaziz University \\ E. Ghandourahc \\ King Abdulaziz University \\ Mohammed A.Taha ( $\square$ mtahanrc@gmail.com ) \\ National research centre
}

\section{Research Article}

Keywords: Al matrix, Hybrid nanocomposites, Powder metallurgy, Strength, Wear rate, Younge's modulus, Corrosion

Posted Date: May 19th, 2021

DOl: https://doi.org/10.21203/rs.3.rs-519252/v1

License: (c) (i) This work is licensed under a Creative Commons Attribution 4.0 International License. Read Full License

Version of Record: A version of this preprint was published at Silicon on August 17th, 2021. See the published version at https://doi.org/10.1007/s12633-021-01284-0. 
The effect of different fly ash and vanadium carbide contents on the various properties of hypereutectic Al-Si alloys-based hybrid nanocomposites

\author{
Waheed S. AbuShanab a ${ }^{\text {a }}$ Essam B. Moustafa ${ }^{\text {b }}$, E. Ghandourah ${ }^{\mathrm{c}}$, \\ Mohammed A. Taha ${ }^{\mathrm{d} *}$ \\ ${ }^{a}$ Marine Engineering Department, Faculty of Maritime Studies and Marine \\ Engineering, King Abdulaziz University, Jeddah 21589, Saudi Arabia \\ ${ }^{b}$ Mechanical Engineering Departments, Faculty of Engineering, King Abdulaziz. \\ University, Jeddah 21589, Saudi Arabia \\ ${ }^{c}$ Department of Nuclear Engineering, Faculty of Engineering, King Abdulaziz \\ University, Jeddah 21589, Saudi Arabia \\ ${ }^{d}$ Solid State Physics Department, National Research Centre, El Buhouth St., \\ Dokki, 12622 Giza, Egypt.
}

\title{
Corresponding author
}

Mohammed A. Taha*

mtahanrc@gmail.com

\begin{abstract}
Recently, the attention of scientists has been devoted to improving the various properties of aluminum alloys such as strength, elastic modulus, and wear and corrosion. In this respect, the preparation of hybrid nanocomposites containing two ceramic reinforcements is a promising strategy for enhancing the aformentioned properties for use in various industrial applications. Therefore, powder metallurgy technique was used to manufacture hybrid nanocomposites from $\mathrm{Al}-\mathrm{Si}$ matrix reinforced with different weight percentages of vanadium carbide (VC) and fly ash (FA) particles. Then, the prepared powders' microstructure and particle size


distributions were examined by SEM technique and diffraction particle size analyzer. The prepared powders were sintered in an argon atmosphere and subsequently, their physical, elastic and mechanical properties, and wear and corrosion behavior were measured. The results showed that the addition of 10 wt.\% VC and 10 wt.\% FA nanoparticles resulted in a decrease in Al-Si alloy particle sizes up to $47.8 \mathrm{~nm}$ and improved microhardness yield, strength, and Young's modulus to 161,145 and 64\%, respectively. Also, it remarkably decreased the rate of wear and corrosion to 40 and $67 \%$, respectively.

\section{Keywords}

Al matrix; Hybrid nanocomposites; Powder metallurgy; Strength; Wear rate; Younge's modulus; Corrosion.

\section{Introduction}

In recent years, technological progress has required unique properties such as high strength, high corrosion resistance, better fatigue strength, and high wear resistance, etc., which cannot be achieved in metals alone. In this context, researchers looked at manufacturing metal-based nanocomposites. Hypereutectic $\mathrm{Al}-\mathrm{Si}$ alloy is the preferred material as production matrix (ASMCs) reinforced with ceramic particles. Because of these attractive properties, ASMCs have a strong role in different industrial fields such as car enterprises, aerospace, defense, and military industries [1-3]. The reasons behind Al-Si alloy being considered the best choice as a matrix for such desirable nanocomposites are its low ductility coupled with high strength compared to pure Al. When two or more reinforcements are added to this alloy, the resulting hybrid nanocomposite achieves superior properties such as outstanding mechanical properties, wear behavior and thermal expansion coefficients $[4,5]$. 
Al-Si alloys also show high resistance to corrosion in air which, according to the literature, can be attributed to their ability to form an oxide layer that protects them from the attack of corrosive solutions [6,7]. In order to further improve their corrosion resistance, some corrosion inhibitors can be added to modify the neighboring environment. Notably, these corrosion inhibitors include alloying elements, anodizing the surface, and painting their surfaces with a protective coating layer [8,9].

Several studies have investigated the properties of $\mathrm{Al}$ and $\mathrm{Al}$ alloy hybrid matrix nanocomposites. For example, Baradeswaran et al. [10] used the liqid casting method to produce $\mathrm{Al}$ matrix hybrid nanocomposites reinforced with boron carbid and graphite particles. The results showed a clear improvement in nanocomposite hardness and wear rate with increasing reinforcement contents. Ashrafi et al. [11] studied the effect of $\mathrm{Fe}_{3} \mathrm{O}_{4}$ and $\mathrm{SiC}$ reinforcments on the microstructure, tribology and corrosion properties of $\mathrm{Al}$ matrix. They clearly observed that a clear improvement in the coefficient of friction and the corrosion rate with the addition of reinforcements.

Fly ash (FA) particles are potential discontinuous dispersants used as reinforced $\mathrm{Al}$ and $\mathrm{Al}$ alloy matrix, as they are available in large quantities as secondary waste in thermal power plants, in low cost and its density is low. Moreover, addition of FA improves wear resistance, mechanical and damping properties, and reduces the density of $\mathrm{Al}$ alloys matrix [12]. Under the effect of its particle size, the interaction of particles with dislocations easily occurs which consequently, gives a great significance on the enhancement of densification of the sintered samples and, consequently, the improvement of wear, corrosion resistance and mechanical properties [13]. It is substantial to underline that there are many several efficient routes for producing $\mathrm{Al}$ and its alloy matrix nanocomposites, such as fraction stir [14], squeeze casting [15], stir casting [16], and mechanical alloying 
(MA) [17,18]. The latter is a modern, cost-effective tool for good dispersion of a reinforcement in a metal matrix giving a uniform distribution particles in the microstructure $[19,20]$. Notably, there are various types of ball mill, which are essential for MA, to perform the required fracture and welding process for powder particles bearing in mind that MA process is highly dependent upon the main parameters like milling time, speed, mill type, ball-to-powder (BPR) ratio and vial/ball material which consequently, control the size as well as shape of the produced reinforcing material [20-22]. Based on the abovementioned advantages of MA, this process is able to fabricate various AMHCs with desirable properties [23].

Al369 aluminum alloy is known to have poor wear resistance, corrosion rate, mechanical and elastic properties, which limit its uses in various industries. Many attempts have been done to improve the above-mentioned properties of different $\mathrm{Al}$ alloys by different oxides such as $\mathrm{Al}_{2} \mathrm{O}_{3}$ [24, 25], nitrides [26], carbides such as $\mathrm{TiC}$ and $\mathrm{SiC}[27,28]$ and borides [29,30] having in mind that the most common are $\mathrm{Al}_{2} \mathrm{O}_{3}$ and $\mathrm{SiC}$. However, according to the authors' knowledge, this study is

possibly the first attempt to improve the different properties of Al-Si alloy using the combination of VC and FA. Therefore, the main objective of present study is to use FA and $\mathrm{VC}$ nanoparticles as reinforcements to produce $\mathrm{Al}$ matrix hybrid composites by powder metallurgy method to improve its different properties.

\section{Materials and experimental setup}

In this work, we selected an A1356 alloy as a matrix, and vanadium carbid (< $75 \mathrm{~nm})$ and FA $(<80 \mathrm{~nm})$ particles used as reinforced with various weight percentages. The composition of Al356 alloy and fly ash are listed in Tables $1 \& 2$, while the batch compositions designed for nanocomposites with an Al 356 alloy 
matrix, along with their abbreviations, are tabulated in Table 3 . The nanocomposites powders were subjected to the a milling process for $20 \mathrm{~h}$ with rotation speed $=550 \mathrm{rpm}$ and $\mathrm{BPR}=20: 1$ having in mind that the milling process was done in a cycle of $2 \mathrm{~h}$ and paused for $2 \mathrm{~h}$. To investigate the morphology of the mechanically alloyed powders, they were characterized using scanning electron microscopy (SEM; Philips XL30). Moreover, particle size was measured using diffraction particle size analyzer to get the average distribution pattern for each powder. Then, the milled powders were pressed and sintered at 500 and $575{ }^{\circ} \mathrm{C}$ in an argon atmosphere for $1 \mathrm{~h}$. Notably, the rule of mixture was carried out to calculate the theoretical densities of samples taking into account the density of the $\mathrm{Al}-\mathrm{Si}$ alloy, $\mathrm{VC}$ and $\mathrm{FA}=2.67,5.77$ and $2.34 \mathrm{~g} / \mathrm{cm}^{3}$, respectively. On the other hand, Archimedes method was carried out to measure both bulk density and apparent porosity. The microstructure of the sintered samples was examined by scanning electron microscopy. Vickers microhardness (Hv) was measured with a Shimadzu-HMV (Japan) according to ASTM: B933-09 as described in Ref. [31]. Furthermore, the compressive tests of the sintered nanocomposites were performed according to ASTM E9-19 standard. The ultimate strength, yield strength, and elongation were calculated from the stress-strain curve; hence the ultimate strength and elongation are the maximum values of stress and strain on stress-strain curve, respectively. On the other hand, yield strength was calculated using the $0.2 \%$ offset principle. By using pulse-echo technique, longitudinal $\left(\mathrm{V}_{\mathrm{L}}\right)$ and shear ultrasonic velocities $\left(\mathrm{V}_{\mathrm{S}}\right)$ were measured. On the opposite side, constants of Lame's (i.e. $\lambda$ and $\mu$ ) were calculated according to the formula present in Refs. [32]:

$$
\begin{aligned}
& \lambda=\rho\left(V_{L}^{2}-2 V_{S}^{2}\right) \\
& \mu=\rho V_{S}^{2}
\end{aligned}
$$


The elastic modulus (L), Young's modulus (E), shear modulus (G), bulk modulus (B) and Poisson's ratio ( $v)$ of the nanocomposites were calculated by equations $[33,34]$ :

$L=\lambda+2 \mu$

$G=\mu$

$E=\mu \frac{3 \lambda+2 \mu}{\lambda+\mu}$

$K=\lambda+\frac{2}{3} \mu$

$v=\frac{\lambda}{2(\lambda+\mu)}$

The wear test was performed using a pin-on-disk tester machine; the specimens were weighed and measured by a digital balance of accuracy of $0.0001 \mathrm{~g}$. All samples were prepared with the same dimensions and polished well using grinding papers with different grades (600 to 4000). The test was carried out using four different loads. The wear rate due to the weight loss was calculated from the following equations (Eq. 1 and 2) [35]:

Net weight $=$ weight before wear-weight after wear

Wear rate $=$ net weight $/$ time

The sintered samples' corrosion rate was determined using static immersion weight loss method at room temperature where each sample was weighed before its immersion in $0.1 \mathrm{M} \mathrm{HNO}_{3}$ solution and later taken out after 24, 48, 72, 96, 120 and $144 \mathrm{~h}$. After drying thoroughly, the specimens were weighted again. The weight loss was measured and converted into corrosion rate expressed in $\mathrm{mm}$ penetration per year (mm/year).

\section{Results and discussion}

\subsection{Milled powders}


Fig.1(a-e) illustrates considerable difference between the microstructure of $\mathrm{Al}-\mathrm{Si}$ alloy and the powders of its nanocomposites with different VC and FA contents after milling for $20 \mathrm{~h}$. The most likely explanation for such observations is that during mechanical milling, the Al-Si alloy matrix particles are subjected to deformation (flatting), while both $\mathrm{VC}$ and FA particles undergo fragmentation. When the particles of Al-Si alloy matrix (ductile particles) start to weld, the reinforcement particles come between two or more matrix particles at the moment of ball collision. As a result, the reinforcement particles reside at the interfacial boundaries of the particles of the welded matrix, and the result is the formation of true nanocomposite powders [23]. It is interesting to note that these decreases in particles sizes due to increased local plastic deformation in the vicinity of $\mathrm{VC}$ and FA particles. Moreover, the ceramics particles act as milling balls and can cause a higher energy transfer to the Al-Si alloy matrix.

The particle size distribution of the milled powders samples as shown in Fig. 2. As the VC and FA content increased, the particle size decreased and the distribution shifted to smaller sizes. The mean particle sizes of the A10, Al5, A110, A15, and A120 samples were 94.8, 87.7, 74.3, 61.2, and $47.8 \mathrm{~nm}$, respectively.

\subsection{Physical properties}

It is well-known that pressing milled nanocomposites powders is an important step for obtaining bulk materials after the mechanical alloying process. Therefore, this step controls the porosity and the shape of the final sintered nanocomposites [36]. The bar graph that explains the relative density and apparent porosity of the sintered samples for $1 \mathrm{~h}$ at 500 and $575^{\circ} \mathrm{C}$ as a function of $\mathrm{VC}$ and FA weight percentages is represented in Fig. 3. By considering the theoretical densities of $\mathrm{Al} 0, \mathrm{Al}$, Al10, Al15, and Al20 samples=2.67, 2.697, 2.724, 2.752, and 2.775 $\mathrm{g} / \mathrm{cm}^{3}$, respectively, the values of the relative densities of Al0 and Al20 after 
sintering at $500{ }^{\circ} \mathrm{C}$ are 93.69 and $86.11 \%$, respectively. On the opposite side, those of the apparent porosity is 5.18 and $9.460 \%$, respectively, for the same samples. This result may be because increasing the weight percentages of reinforcement in the Al-Si alloy matrix lead to a decrease in the pressing capacity of the sintered samples because of the higher hardness of the reinforcement particles. Moreover, the melting point of the $\mathrm{VC}$ and $\mathrm{FA}$ reinforcement $\left(\approx 2810 \& 1710{ }^{\circ} \mathrm{C}\right.$, respectivly) is much more than that of $\mathrm{Al}$ matrix, and hence, the contents of the increased reinforcement have an inhibitor effect of the sintering process and consequently act as a barrier against diffusion steps during this process [37]. On the contrary, increasing the sintering temperature from 500 to $575{ }^{\circ} \mathrm{C}$ has an effective role in improving the relative density due to formation of necks between particles and increasing bonding between particles [38]. Moreover, the increased sintering temperatures lead to an acceleration of solid-state diffusion and, consequently, better densification behavior [39]. When the sintering temperature $=575^{\circ} \mathrm{C}$, the relative density of the samples decreases from 97.48 to $92.21 \%$ by increasing the reinforcement contents from 0 to $20 \mathrm{wt} . \%$.

\subsection{Microstructure}

Figs. 4 illustrated the SEM images of nanocomposites with different VC and FA contents and sintered at $570{ }^{\circ} \mathrm{C}$ inargon atmosphere. Generally, VC and FA particles are found at the matrix's grain borders, considering the sample has the lowest reinfocements content (A15) exhibits somewhat homogenous distribution for FA and $\mathrm{VC}$ particles noting that this distribution decreases with increased reinforcements contents (A120). Notably, it was also observed that the porosity increased by increasing of reinfocements particles in the studied specimens. However, the elevation of sintering temperature to $575{ }^{\circ} \mathrm{C}$ causes promotion for diffusion process during the heating process, resulting in better densification 
behavior, i.e., nearly reaching full density. The contact border between particles seems to be growing and indicates the achievement of strong reinfocements matrix interfacial bonding, during sintering of the nanocomposites samples, and the absence of pores in the area of reinfocements particles.

\subsection{Elastic and mechanical properties}

The longitudinal $\left(\mathrm{V}_{\mathrm{L}}\right)$ and shear ultrasonic velocities $\left(\mathrm{V}_{\mathrm{S}}\right)$ results were measured using a non-destructive test, i.e. ultrasonic technique for samples sintered at $575{ }^{\circ} \mathrm{C}$ as shown in Fig. 5. It is interesting to see that ultrasonic velocities increase by increasing VC and FA contents. The figures indicate that as the reinforcement contents increased from 0 to $20 \mathrm{wt} . \%$, the $\mathrm{V}_{\mathrm{L}}$ and $\mathrm{V}_{\mathrm{S}}$ values of the samples range from 5503.32 to 6885.29 and 2871.08 to $3501.04 \mathrm{~ms}^{-1}$, respectively. As can be seen from this figure, the elastic moduli exhibit the same trend for ultrasonic velocities. The elastic moduli of the investigated nanocomposite samples are shown in Fig. 6. It is clear from the figure that the family of elastic moduli exhibits the same trend of ultrasonic velocities. For example, in the Al0 sample (i.e., the free content of CV and FA particles), the elastic modulus and Poisson's ratio are 80.87 GPa and 0.3130, respectively. Interestingly, they increase to $131.45 \mathrm{GPa}$ and 0.3256, respectively, when $\mathrm{VC}$ and FA refinement increases to 20 wt. \% (Al20). This marked improvement of ultrasonic velocities and elastic moduli due to the addition of highly hard nano-reinforcement particles as reinforcement and fully corresponds to the precise results of microhardness and compressive strength.

The average microhardness values of the Al-Si alloy and nanocomposite samples sintered at $575{ }^{\circ} \mathrm{C}$ are presented in Fig. 7. It is noted from the results that pronounced increase in the values of microhardness with increasing the different content of $\mathrm{VC}$ and FA particles. The microhardness of the Al-Si alloy matrix 
increases from 68.17 to $119.21 \mathrm{Hv}$ as a result of the addition of $10 \mathrm{wt} . \% \mathrm{VC}$ and 10 wt.\% FA particles. Generally, the increase in nanocomposites samples' microhardness can be attributed to various reasons, including homogenous distribution of reinforcement in the matrix, decreased grains sizes of matrix with successive increases in reinforcement contents, and the existence of hard ceramic particles (i.e., VC \& FA) [10]. This enhancement can be better understood by noting the following Eqns. (10) [40].

$\mathrm{H}_{\mathrm{c}}=\mathrm{H}_{\mathrm{Al}} \mathrm{F}_{\mathrm{Al}}+\mathrm{H}_{\mathrm{V}} \mathrm{F}_{\mathrm{V}}+\mathrm{H}_{\mathrm{F}} \mathrm{F}_{\mathrm{F}}$

where $\mathrm{H}_{\mathrm{c}}, \mathrm{H}_{\mathrm{Al}}, \mathrm{H}_{\mathrm{V}}$ and $\mathrm{H}_{\mathrm{F}}$ are microhardness of the nanocomposite, Al-Si matrix, $\mathrm{Vc}$ and $\mathrm{FA}$, respectivly. On the other hand, $\mathrm{F}_{\mathrm{Al}}, \mathrm{F}_{\mathrm{V}}$ and $\mathrm{F}_{\mathrm{F}}$ are the volume fraction of matrix Vc and FA, respectivly, respectively.

Fig. 8 shows the compressive stress-strain curves of samples. It can be observed that, for the same sintering temperature, Al-Si alloy (A10) has a lower yield strength $\left(\sigma_{\mathrm{y}}\right)$ and ultimate compressive strength $\left(\sigma_{\mathrm{ucs}}\right)$ and higher elongation $(\varepsilon)$ than the other nanocomposite samples. From the graphs obtained from the compression tests of the sintered samples, the values of $\sigma_{\mathrm{ucs}}, \sigma_{\mathrm{y}}$, and $\varepsilon$ were calculated and shown in Fig.9 . According to the results, both $\sigma_{\mathrm{ucs}}$ and $\sigma_{\mathrm{y}}$ of all nanocomposites samples gradually increase, while elongation reduces with increasing $\mathrm{VC}$ and FA contents, which agree with the observed trend in their microhardness results as shown in Fig. 7. The $\sigma_{\mathrm{ucs}}, \sigma_{\mathrm{y}}, \varepsilon$ are $278.72 \mathrm{MPa}, 119.54$ $\mathrm{MPa}, 11.1 \%$ for $\mathrm{Al}$, respectively, and for Al20 were $384.46 \mathrm{MPa}, 170.1 \mathrm{MPa}$, $6.02 \%$, respectively. Generally, many factors are responsible for the increases in ultimate and yield strength, while the decreases in the elongation of $\mathrm{Al}$ alloy matrix reinforced with different reinforcement content is influenced by the following factors:

(i) Thermal-mismatch strengthening 
Thermal mismatch strengthening is related to the large difference between the CTE of Al-Si alloy matrix, $\mathrm{VC}$ and FA particles, contributing to producing thermally induced residual stresses [41]. Even with small temperature changes, the thermal stresses generated in the Al-Si alloy matrix, significantly contribute to high dislocation density in the vicinity of the interface and, therefore, strengthen the nanonanocomposite.

(ii) Orowan strengthening

The Orowan strengthening effect plays a vital role in enhancing Al-Si matrix nanocomposites' mechanical properties, resulting from homogenous dispersion of hard VC and FA phase into Al alloy matrix, which acts as a barrier for dislocation movement. Consequently, dislocation loops are created around reinforcement particles, causing an increase in the stress required for more deformation.

(iii) Load transfer from the $\mathrm{Al}$ alloy to the $\mathrm{VC}$ and FA nanoparticles During compressive testing, the load transfer, $\sigma_{\text {load }}$, between the hard ceramics particles and Al-Si alloy, especially, if the connection between reinforcement particles and Al-Si alloy matrix is good enough as explained by eqn. (11) [42]:

$\sigma_{\text {load }}=0.5 \mathrm{~V}_{\mathrm{f}} \sigma_{\mathrm{Y}}$

where $\sigma_{\mathrm{Y}}$ is the yield strength of the matrix

It can be concluded that the work hardening capacity $\left(\mathrm{H}_{\mathrm{c}}\right)$ of samples is reduced by adding various reinforcement contents as shown in Fig 9(b). The $\mathrm{H}_{\mathrm{c}}$ of nanocomposites samples can be calculated using the value of $\sigma_{\mathrm{ucs}}$ and $\sigma_{\mathrm{y}}$ according to Eqn. (12):

$\mathrm{Hc}=\frac{\sigma_{\mathrm{UCS}}-\sigma_{\mathrm{Y}}}{\sigma_{\mathrm{Y}}}$

It is interesting to observe that $\mathrm{H}_{\mathrm{c}}$ of pressed nanocomposites decreases with the increase in the ceramics particle content. The nanocomposites' Hc depends on its yield strength, which is further correlated to grains sizes based on the Hall-Petch 
Equ. If the grain sizes decrease, the difference in the flow resistance between the grain boundaries is also reduced, leading to an increase in the yield strength, leading to decreased work hardening [43].

\subsection{Wear analysis}

Fig. 10 represents the variations in weight loss and wear rate of A10, A15, Al10, A115 and A120 samples with different applied loads of test (10, 20, 30 and $40 \mathrm{~N}$ ). The results point out that nanocomposites samples' wear resistance tends to increase with an increase in VC and FA contents, while it is decreased with increasing of the load. The weight loss of an un-reinforced sample (i.e. A10) at applied loads, i.e. 10, 20, 30 and $40 \mathrm{~N}$ is $12.78,13.48,13.89$ and $14.51 \mathrm{mg}$, respectively. For the sample containing 20 wt. \% of reinforcement (i.e., Al20) at the same applied loads, the weight loss is 7.15, 7.78, 8.39 and $8.73 \mathrm{mg}$, respectively. Furthermore, the wear rate of A10, Al5, Al10, Al15 and Al20 samples when the applied load equals to $40 \mathrm{~N}$ is $0.0242,0.0211,0.0183,0.0166$, and $0.0145 \mathrm{mg} / \mathrm{s}$, respectively. Undoubtedly, the addition of ceramics particles (i.e., $\mathrm{VC}$ and FA) has a positive outcome in the synthesized nanocomposites in which wear resistance is found to be effectively improved [44]. To explain the enhancement of wear resistance of nanocomposites, it is important to highlight that the addition of VC and FA particles to Al alloy results in an enhancement in nanocomposites' microhardness and strength samples as previously discussed, and therefore, the wear rate decreases according to Archad Eqn. (13) [45]:

$$
\mathrm{W}=\frac{\mathrm{kP}}{\mathrm{H}}
$$

$\mathrm{W}$ is wear rate, $\mathrm{K}$ is a wear coefficient (constant value), $\mathrm{P}$ is the load, and $\mathrm{H}$ is the specimen's Vickers hardness. 
Furthermore, the increase of microhardness is consistent with a decrease in a real area of contact. It is well-accepted that real area of contact can be expressed in terms of the ratio of the normal load to the hardness of the pin material, and accordingly, decreased real area of contact leads to considerable decreases in wear rate [46]. On the other hand, increases in weight loss and wear rate with increases in the applied load and the surface temperature encourage surface softening, causing more surface and subsurface damage, resulting in decreased wear resistance [12]. One can say that both wear and loss of metals are highly dependent on an increase in the load as the initial fraction period works to fracture the surface layers, leading to cleaning the surfaces and increasing the strength of connections between surfaces. This process increases the tillage effect between surfaces, which increases the temperature between them, resulting in adhesion and deformation at the surface layers, driving more loss for metals [47].

\subsection{Corrosion analysis}

The weight-loss method was used to evaluate $\mathrm{Al}-\mathrm{Si}$ or nanocomposites specimens' corrosion behavior in an acidic medium. Generally, many factors affect the corrosion behavior of the studied nanocomposites such as compaction, density, sintering, and weight percentages of $\mathrm{VC}$ and FA. In this sense, the weight loss and corrosion rate of A10, A15, Al10, Al15 and Al20 sintered samples were immersed in a $0.1 \mathrm{~N} \mathrm{HNO}_{3}$ at room temperature $\left(30{ }^{\circ} \mathrm{C}\right)$, as a function of exposure time were examined and represented in Fig. 11. It is interesting to observe that the weight loss of $\mathrm{Al}$ alloy matrix nanocomposites increases with increasing of exposure time, and therefore, the corrosion rate decreases. The weight loss of the sample increases with increases in exposure time because increasing contact period with acidic medium decreases in corrosion rate [48]. The weight loss of Al0 sample immersed for 24,96 , and $168 \mathrm{~h}$ are $12.24,22.78$, and $31 \mathrm{mg}$, respectively, and for sample 
A120, at the same immersion times, is $8.08,14.40$, and $18.52 \mathrm{mg}$, respectively. It could also be observed that both weight loss and corrosion rate decrease by increasing VC and FA contents. Generally, the particles of ceramic reinforcements remain the same, i.e. without a noticeable corrosion behavior, and consequently, the existence of ceramics particles in the surface of the nanocomposite samples that will protect the surface layer in the acidic medium [49.50]. The Al0 sample shows that the corrosion rate is higher compared to the Al20 nanocomposite samples. The reason behind this result is that VC and FA are a ceramic material which possesses high corrosion resistance, i.e. it remains inert and unaffected by the acidic medium throughout the corrosion tests. The corrosion rate of A10, Al5, Al10, Al15, and Al20 samples submerged for $168 \mathrm{~h}$ are 1.27, 1.18, 1.06, 0.90, and 0.77 mmpy, respectively.

\section{Conclusions}

In the current study, the $\mathrm{VC}$ and FA enhanced $\mathrm{Al}-\mathrm{Si}$ hybrid nanocomposites were prepared using powder metallurgy. The following conclusions were drawn

- It was observed that the nanocomposites prepared by the method of mechanical alloying had a good distribution of VC and FA particles in a matrix with noticeable agglomerations.

- The particle sizes decreased with increasing the weight percentages of VC and FA particles until they reached $47.8 \mathrm{~nm}$ for the higher contents of the reinforcement (A120 sample).

- The relative density of the nanocomposite decreased with increasing the contents of reinforcements, while the apparent porosity had an opposite trend.

- The ultrasonic velocities of the sintered samples increased with the increase in FA and $\mathrm{VC}$ contents, which led to an increase in the value of the elastic 
moduli. The elastic and bulk moduli were enhanced to 61 and $66 \%$, respectively, after adding $20 \mathrm{wt} . \%$ of reinforcements (A120).

- Microhardness, ultimate, and yield strength were improved, while elongation and work hardening were reduced with increasing the weight percentages of reinforcement. The maximum values of the microhardness and ultimate strength of the A120 sample were recorded, i.e., $\sim 1.7$ and 1.4 times, respectively higher than those of the Al0 sample.

- The wear rates of specimens decreased as the contents of the reinforcements increased with increase in the application. For the applied load of $10 \mathrm{~N}$, the corrosion rate of the Al-Si alloy decreased by about $44.1 \%$ for the sample Al20.

- The corrosion rate of nanocomposites has been found to be reduced by increasing the exposure time and weight percentages of ceramic reinforcements.

\section{Figures caption}

Fig.1 SEM micrographs of the milled powders (a) Al0, (b) Al5, (c) Al10, (d) Al15 and (e) A120 samples.

Fig.2. Particle size distribution of the milled powders in various VC and FA contents.

Fig. 3. (a) The relative density and (b) the apparent porosity of the prepared sintered nanocomposites samples.

Fig.4. SEM micrographs of a) A10, b) A15 and c) A120 samples sintered at $575^{\circ} \mathrm{C}$.

Fig.5. Ultrasonic velocities of nanocomposite samples sintered at $575{ }^{\circ} \mathrm{C}$ versus different contents of VC and FA. 
Fig.6. The group of elastic moduli of nanocomposite samples sintered at 575 ${ }^{\circ} \mathrm{C}$ versus different contents of VC and FA.

Fig.7. Microhardness of nanocomposites samples sintered at $575{ }^{\circ} \mathrm{C}$ versus $\mathrm{VC}$ and FA contents.

Fig.8. Compressive stress versus strain curve of Al-Si alloy/VC/FA samples sintered at $575{ }^{\circ} \mathrm{C}$.

Fig.9. Ultimate compressive strength, yield strength, elongation, and work hardening capacity of sintered samples.

Fig.10. a) Weight loss and b) wear rate of specimens sintered at $575{ }^{\circ} \mathrm{C}$ for different applied loads.

Fig.11. a) Weight loss and b) corrosion rate of specimens sintered at $575{ }^{\circ} \mathrm{C}$ for different exposure time.

\section{Funding statement}

This project was funded by the deanship of scientific research (DSR) at King Abdulaziz University, Jeddah under grant No. (RG-1-150-38). The authors therefore gratefully acknowledges technical and financial support from DSR.

\section{Conflict of Interest}

The manuscript was written through contributions of all authors. All authors have given approval to the final version of the manuscript. The authors declare that they have no competing interests.

\section{Author contributions}

\section{1- Waheed S. AbuShanab}

- Project administration

- Funding acquisition

- Formal analysis

\section{2- Essam B. Moustafa}


- Data curation

- Participation in Writing the original draft

3- E. Ghandourah

- Methodology

- Formal analysis

4- Mohammed A. Taha

- Investigation

- Participation in Writing the original draft

- Writing - review - editing

\section{Availability of data and material}

The data and materials are available of this article

\section{Compliance with ethical standards}

The authors have declared that no competing interests exist

\section{Consent to participate}

The authors confirm that they have contribution in this article

1. Waheed S. AbuShanab

2. Essam B. Moustafa

3. E. Ghandourah

4- Mohammed A. Taha

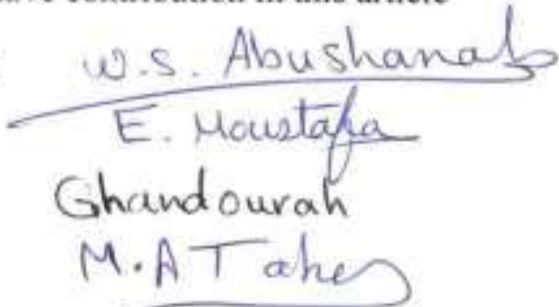

\section{Consent for Publication}

The authors agree to publish this article in its current form

\section{Acknowledgment}


This project was funded by the deanship of scientific research (DSR) at King Abdulaziz University, Jeddah under grant No. (RG-1-150-38). The authors therefore gratefully acknowledges technical and financial support from DSR.

\section{References}

[1] Taha MA , Youness RA, Ibrahim MA (2021) Evolution of the physical, mechanical and electrical properties of SiC-reinforced Al 6061 nanocomposites Prepared by Stir Cast Method, Biointerface Res Appl 11(2):8946 - 8956.

[2] Park B, Lee D, Jo I, Lee SB, Lee SK, Cho S (2020) Automated quantification of reinforcement dispersion in $\mathrm{B} 4 \mathrm{C} / \mathrm{Al}$ metal matrix composites, Compos 181:107584.

[3] Zawrah MA, Mostafa H, Taha MA (2018) Effect of SiC content on microstructure, mechanical and electrical properties of sintered Al-20Si-xSiC nanocomposites fabricated by mechanical alloying, Mater Res Express 61:25014.

[4] Kumar KR, Pridhar T, Balaji VSS (2018) Mechanical properties and characterization of zirconium oxide $\left(\mathrm{ZrO}_{2}\right)$ and coconut shell ash (CSA) reinforced aluminium (Al 6082) matrix hybrid nanocomposite, Alloys Compds 765:171-179.

[5] Kareem A, Qudeiri JA, Abdudeen A, Ahammed T, Ziout A (2021) A review on AA 6061 metal matrix composites produced by stir casting, Mater 14(1):1-12.

[6] John CF, Paul RC, Singh SCE, Jacobjose J, Ramkumar T, Hikku GS, Sharma RK, Sengottuvel P (2018) Corrosion behavior of $\mathrm{ZrC}$ particles reinforcement with Al-12Si composites by weight loss method using acidic media, B Pol Acad SciTech 66: 9-16.

[7] Nataraj G, Sudhakar A, Pruthviraj RD, Ramesh S (2015) Weight loss corrosion studies of aluminium-7075 alloy reinforced with silicon carbide particulates composites in acid chloride medium, Int J Eng Sci Res Technol 4:538-541. 
[8] Bai Q, Zhang L, Ke L, Zhu P, Ma Y, Xi S, Zhou B (2020) The effects of surface chemical treatment on the corrosion behavior of an $\mathrm{Al}-\mathrm{B}_{4} \mathrm{C}$ metal matrix nanocomposite in boric acid solutions at different temperatures, Mat Today In press.

[9] Sherif EM, Abdo HS, Khalil KA, Nabawy AM (2016) Effect of Titanium Carbide Content on the Corrosion Behavior of Al-TiC composites Processed by High Energy Ball Mill, Int J Electrochem Sci 11:4632 - 4644.

[10] Baradeswaran A, Vettivel SC, Perumal AE, Selvakumar N, Issac RF (2014) Experimental investigation on mechanical behaviour, modelling and optimization of wear parameters of $\mathrm{B}_{4} \mathrm{C}$ and graphite reinforced aluminium hybrid composites, Mater Des 63:620-632

[11] Ashrafi N, Azmah Hanim MA, Sarraf M, Sulaiman S, Hong TS (2020) Microstructural, tribology and corrosion properties of optimized $\mathrm{Fe}_{3} \mathrm{O}_{4}-\mathrm{SiC}$ reinforced aluminum matrix hybrid nano filler nanocomposite fabricated through powder metallurgy method, Mater 13: 1-22.

[12] Dwivedi SP, Sharma S, Mishra RK (2015) microstructure and mechanical behavior of $\mathrm{A} 356 / \mathrm{SiC} / \mathrm{Fly}$-ash hybrid composites produced by electromagnetic stir casting, J Braz Soc Mech Sci Eng 37:56-57.

[13] Pérez OR, García-Hinojosa JA, Rodríguez Gómez FJ, Mejia-Sintillo S, Salinas-Bravo VM, Lopes-Sesenez R, Gonzalez-Rodriguez JG, Garcia-Pérez CA (2019) Corrosion Behavior of A356/SiC Alloy Matrix composites in 3.5\% NaCl Solution, Int J Electrochem Sci 14:7423-7436.

[14] E.B. Moustafa, A.O. Mosleh, Effect of (Ti-B) modifier elements and FSP on 5052 aluminum alloy, Alloy. Compd. 825, 153745 (2020).

[15] Dhanashekar M, Kumar VS (2014) Squeeze casting of aluminium metal matrix composites- an overview, Procedia Eng 97:412-420. 
[16] Gopalakrishnan S, Murugari N (2012) Production and wear characterization of AA 6061 matrix titanium diboride particulate reinforced nanocomposite by enhanced stir casting method, Compos B 43:302-308.

[17] Dalai R, Nath S, Mishra DK, Behera G (2020) Fabrication of an Al matrix hybrid nanocomposite reinforced with $\mathrm{Cu}, \mathrm{Al}_{2} \mathrm{O}_{3}$ and $\mathrm{TiC}$ by mechanical alloying, Mater Today 26:1841-1844.

[18] Youness RA, Taha MA, Ibrahim M (2021) Dense alumina-based carbonated fluorapatite nanobiocomposites for dental applications, Mater Chem Phys 257:123264.

[19] Youness RA, Taha MA, Ibrahim MA, In vitro bioactivity, molecular structure and mechanical properties of zirconia-carbonated hydroxyapatite nanobiocomposites sintered at different temperatures, Mater Chem Phys 239:122011.

[20] Taha MA, Nassar AH, Zawrah MA (2020) In-situ formation of nanocomposite having hard outer layer based on aluminum dross reinforced by $\mathrm{SiC}$ and $\mathrm{TiO}_{2}$, Constr Build Mater 248:118638.

[21] Taha MA, Youness RA, Ibrahim M, Biocompatibility, physico-chemical and mechanical properties of hydroxyapatite-based silicon dioxide nanocomposites for biomedical applications, Ceram Int 46:23599-23610.

[22] Al-maamari AEA, Iqbal AA, Nuruzzaman DM, Mechanical and tribological characterization of self-lubricating $\mathrm{Mg}-\mathrm{SiC}-\mathrm{Gr}$ hybrid metal matrix nanocomposite (MMC) fabricated viamechanical alloying, J Sci-Adv Mater Dev 5:535-544.

[23] Taha MA, Youness RA, Zawrah MF (2019) Review on nanocomposites fabricated by mechanical alloying Int J Miner Metall 26(9):1047-1058.

[24] Al-Mosawi BT, Wexler D, Calka A (2017) Characterization and mechanical properties of $\alpha-\mathrm{Al}_{2} \mathrm{O}_{3}$ particle reinforced aluminium matrix composites, 
synthesized via uniball magneto-milling and uniaxial hot pressing, Adv Powder Technol 28(3):1054-1064

[25] Ahamed H, Senthilkumar V (2011) Consolidation behavior of mechanically alloyed aluminum based nanocomposites rein-forced with nanoscale $\mathrm{Y}_{2} \mathrm{O}_{3} / \mathrm{Al}_{2} \mathrm{O}_{3}$ particles, Mater Charact 62 (12):1235-1249.

[26] Bhatia RS, Kudlipsingh K (2017) An experimental analysis of aluminium metal matrix composite using $\mathrm{Al}_{2} \mathrm{O}_{3} / \mathrm{B}_{4} \mathrm{C} / \mathrm{Gr}$ particles, Int J Adv Res Comput Sci (2017). 8:83-90.

[27] Erman A, Groza J, Li X, Choi H, Cao G (2012) Nanoparticle effects in cast Mg-1 wt\% SiC nano-composites, Mater Sci Eng A 558:4339-4343.

[28] Ghasali E, Fazili A, Alizadeh M, Shirvanimoghaddam K, Ebadzadeh T (2017) Evaluation of microstructure and mechanical properties of $\mathrm{Al}-\mathrm{TiC}$ metal matrix composite prepared by conventional, microwave and spark plasma sintering methods, Mater. 10 (11):1255.

[29] Gobalakrishnan B, Lakshminarayanan PR, Varahamoorthi R (2018) Mechanical properties of Al 6061/TiB2 in-situ formed metal matrix composites, $\mathrm{J}$ Adv Microsc Res 13(1):125-130.

[30] Reddy PV, Kumar GS, Krishnudu DM, Rao HR (2020) Mechanical and wear performances of aluminium-based metal matrix composites: a review, J. BioTribo-Corrosion 6:83.

[31] AbuShanab WS, Moustafa EB, Taha MA, Youness RA (2020) Synthesis and structural properties characterization of titania/ zirconia/calcium silicate nanocomposites for biomedical applications, Appl Phys A 787:1-12. 
[32] Taha MA, Youness RA, Zawrah MF (2020) Phase composition, sinterability and bioactivity of amorphous nano- $\mathrm{CaOSiO}_{2}-\mathrm{CuO}$ powder synthesized by sol-gel technique, Ceram Int 46:24462-24471.

[33] Taha MA, Youness RA, El-Bassyouni GT, Azooz MA (2020) FTIR spectral characterization, mechanical and electrical properties of $\mathrm{P}_{2} \mathrm{O}_{5}-\mathrm{Li}_{2} \mathrm{O}-\mathrm{CuO}$ glassceramics, Silicon.

[34] Moustafa EB, Taha MA (2020) Preparation of high strength graphene reinforced $\mathrm{Cu}$-based nanocomposites via mechanical alloying method: microstructural, mechanical and electrical properties, Appl Phys A 126:220 .

[35] Moustafa EB, Melaibari A, Basha M (2020) Wear and microhardness behaviors of AA7075/SiC-BN hybrid composite surfaces fabricated by friction stir processing, Ceram Int 46:16938-16943.

[36] Elmahdy M, Abouelmagd G, Mazen AA (2018) Microstructure and properties of $\mathrm{Cu}-\mathrm{ZrO}_{2}$ nanocomposites synthesized by in situ Processing, Mater Res 21:1-11. [37] Ağaoğullar D (2019) Effects of $\mathrm{ZrC}$ content and mechanical alloying on the microstructural and mechanical properties of hypoeutectic Al-7 wt.\% $\mathrm{Si}$ composites prepared by spark plasma sintering, Ceram Int 45:13257-13268.

[38] Wah A, Muhamad N, Sulon AB, Ahmad RN (2016) Effect of Sintering Temperature on Density, Hardness and Strength of MIM Co30Cr6Mo Biomedical Alloy, J Jpn Soc Powder Metall, 63:434- 437.

[39] Youness RA, Taha MA, Ibrahim MA (2017) Effect of sintering temperatures on the in vitro bioactivity, molecular structure and mechanical properties of titanium/carbonated hydroxyapatite nanobiocomposites, Mol Struct 1150:188-195. 
[40] Moustafa EB, AbuShanab WS, Ghandourah E, Taha MA (2020), Microstructural, mechanical and thermal properties evaluation of $\mathrm{AA6061/} / \mathrm{Al}_{2} \mathrm{O}_{3^{-}}$ BN hybrid and mono composite surface, JMRT 9 (6):15486-15495.

[41] Chen G, Wan J, HE N, Zhang H, han F, Zhang Y (2018) Strengthening mechanisms based on reinforcement distribution uniformity for particle reinforced aluminum matrix composites, Trans Nonferrous Met Soc China. 28:2395-2400.

[42] Habibnejad K, Mahmudi R, Poole WJ (2009) Enhanced properties of Mgbased nano-composites reinforced with $\mathrm{Al}_{2} \mathrm{O}_{3}$ nano-particles, Mater Sci Eng A 519:198-203.

[43] Alizadeh A, Maleki M, Abdollahi A (2017) Preparation of super-high strength nanostructured $\mathrm{B}_{4} \mathrm{C}$ reinforced $\mathrm{Al}-2 \mathrm{Cu}$ aluminum alloy matrix composites by mechanical milling and hot press method: Microstructural, mechanical and tribological Characterization, Adv Powder Technol 28:3274-3287 .

[44] Kumar HGP, Xavior MA (2017) assessment of mechanical and tribological properties of Al 2024- SiC - graphene hybrid composites, Procedia Eng 174: 992 999.

[45] R. Tyagi R (200) Synthesis and tribological characterization of in situ cast AlTiC compo, Wear. 259:569-576.

[46] Tyagi R (2005) Effect of TiC content on friction and wear behavior of Al-Tic composites, World Tribology congress, 1:3-4.

[47] Al-Samarai RA, Ahmad KR, Al-Douri Y (2012) Effect of load and sliding speed on wear and friction of aluminum- silicon casting alloy, IJSRP 2:1-4.

[48] John CF, Paul RC, Singh SCE, Jacobjose J, Ramkumar T, Hikku GS, Sharma RK, Sengottuvel P (2018) Corrosion behavior of ZrC particles reinforcement with Al-12Si composites by weight loss method using acidic media, Bull Pol Ac: Tech. 66:9-16. 
[49] Zakaria HM (2014) Microstructural and corrosion behavior of $\mathrm{Al} / \mathrm{SiC}$ metal matrix composites, Ain Shams Eng, 5:831-838.

[50] Abubakar MS, Usman B (2019) Investigation of corrosion inhibition potential of ethanol extract of balanites aegyptiaca leaves on mild steel in $1 \mathrm{~m}$ hydrochloric acid solution, Mor J Chem 7:82-97. 


\section{Figures}
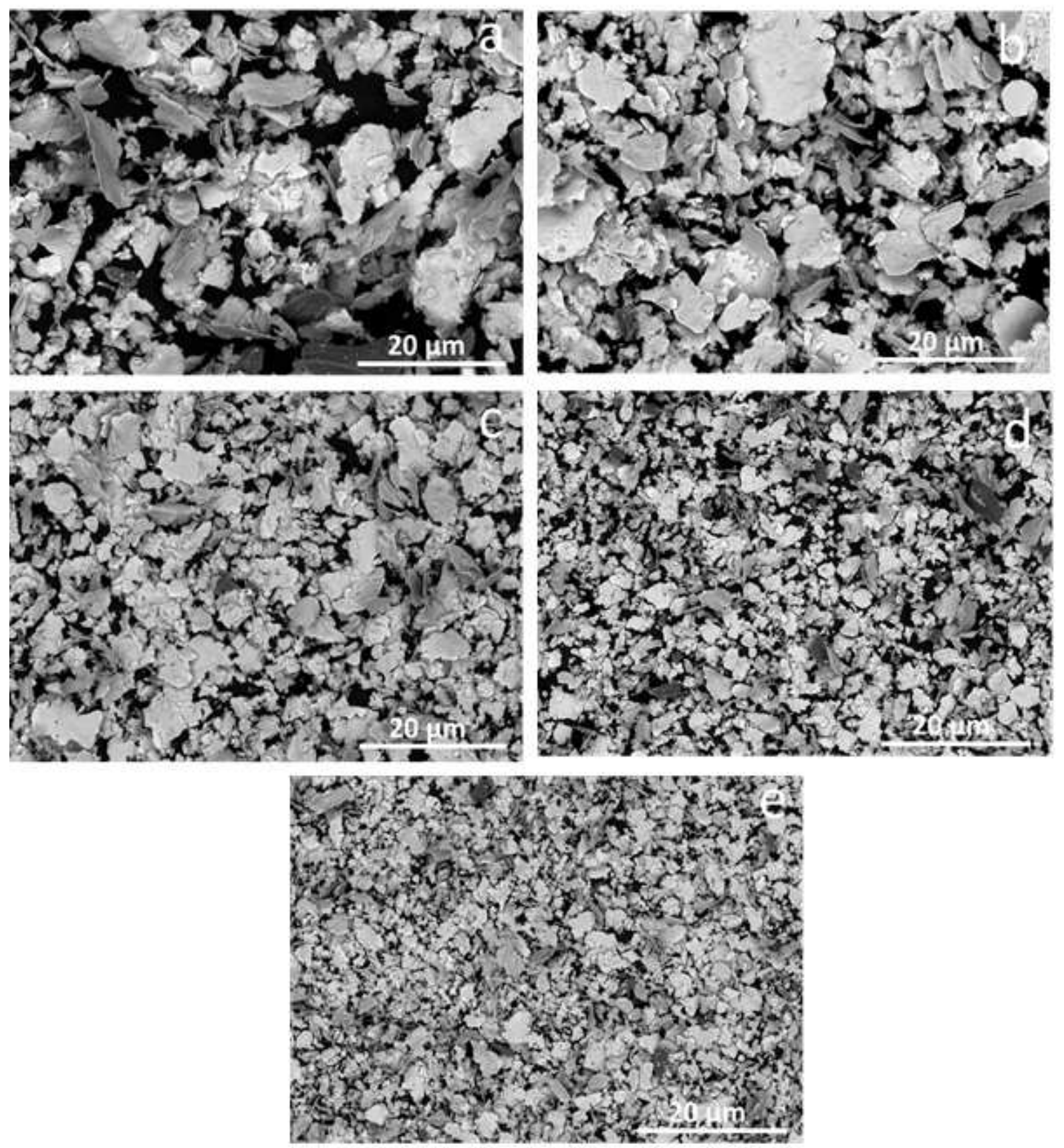

Figure 1

SEM micrographs of the milled powders (a) Al0, (b) Al5, (c) Al10, (d) Al15 and (e) Al20 samples. 

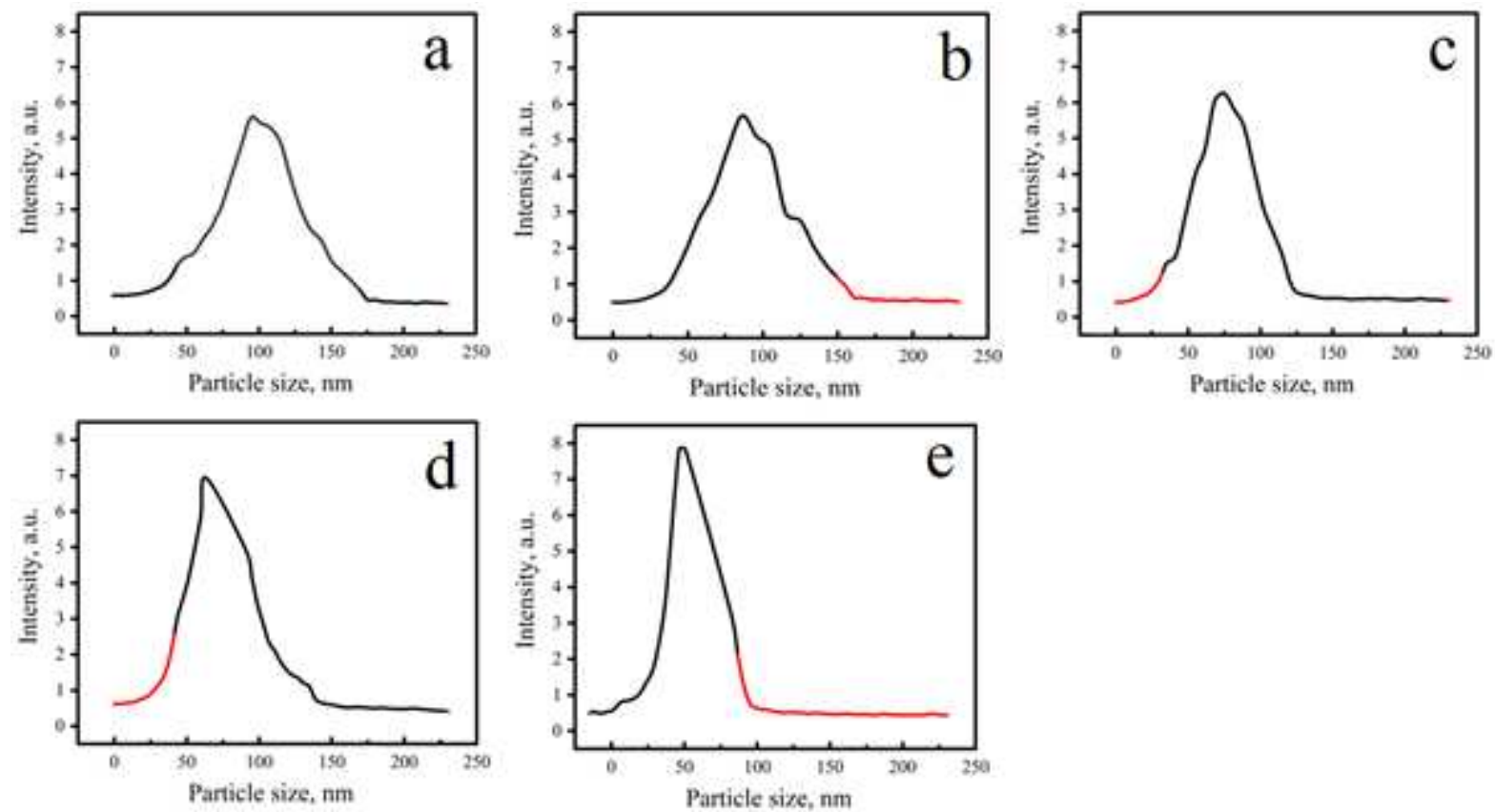

Figure 2

Particle size distribution of the milled powders in various VC and FA contents.
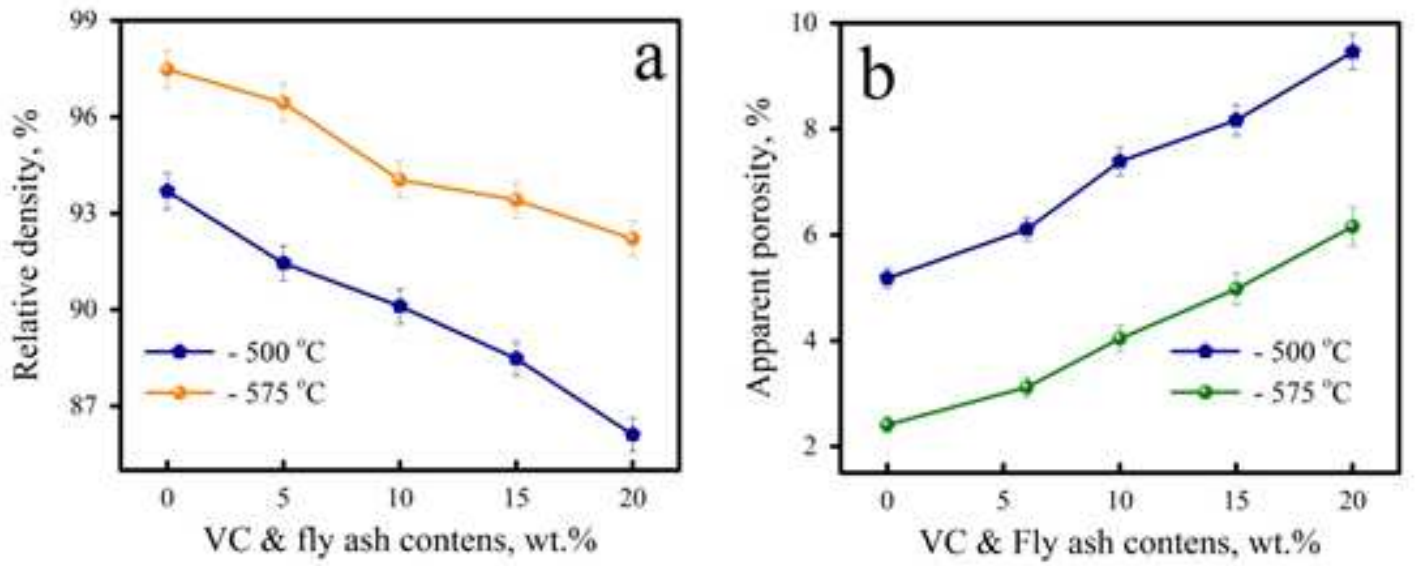

Figure 3

(a) The relative density and (b) the apparent porosity of the prepared sintered nanocomposites samples. 

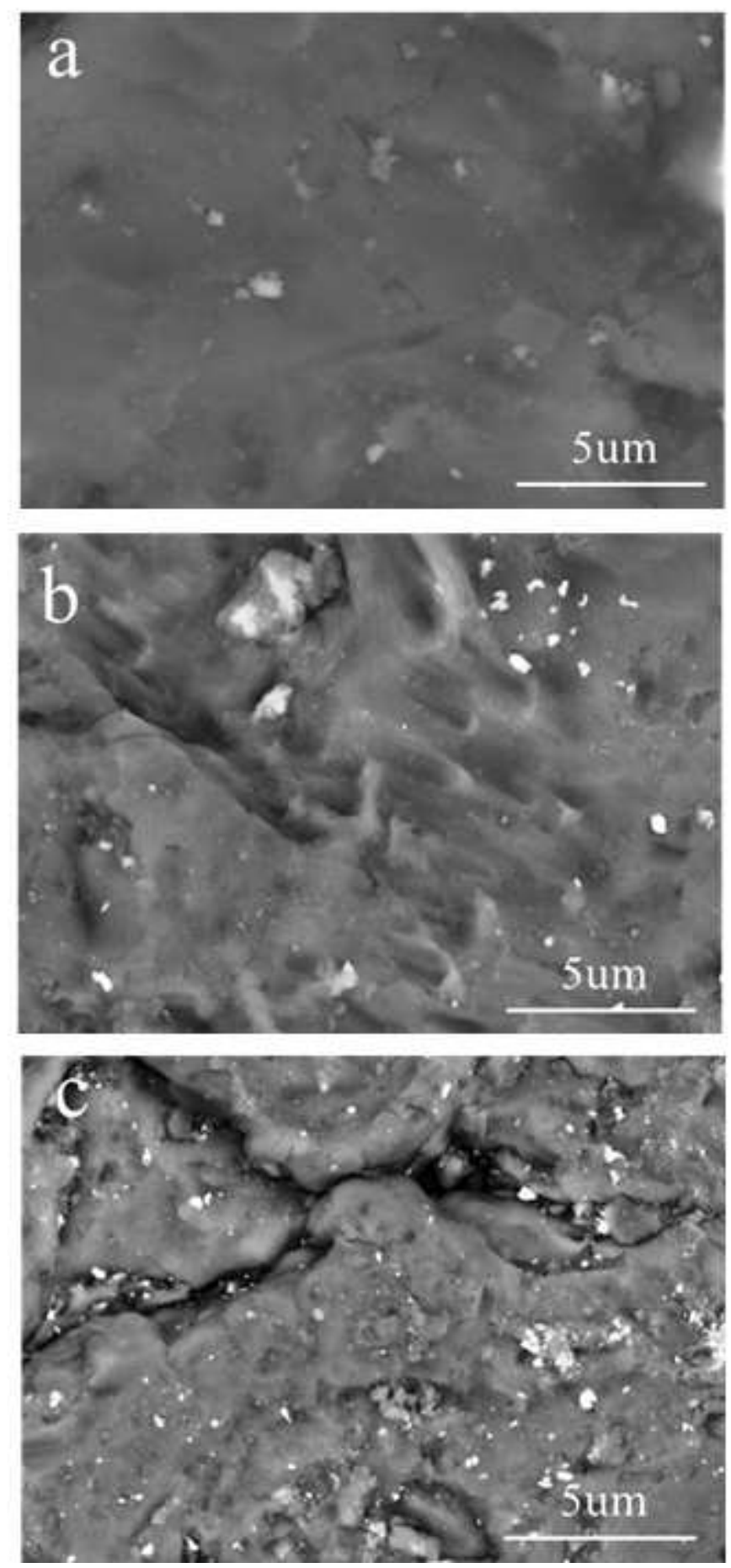

Figure 4

SEM micrographs of a) Al0, b) Al5 and c) Al20 samples sintered at $575^{\circ} \mathrm{C}$. 


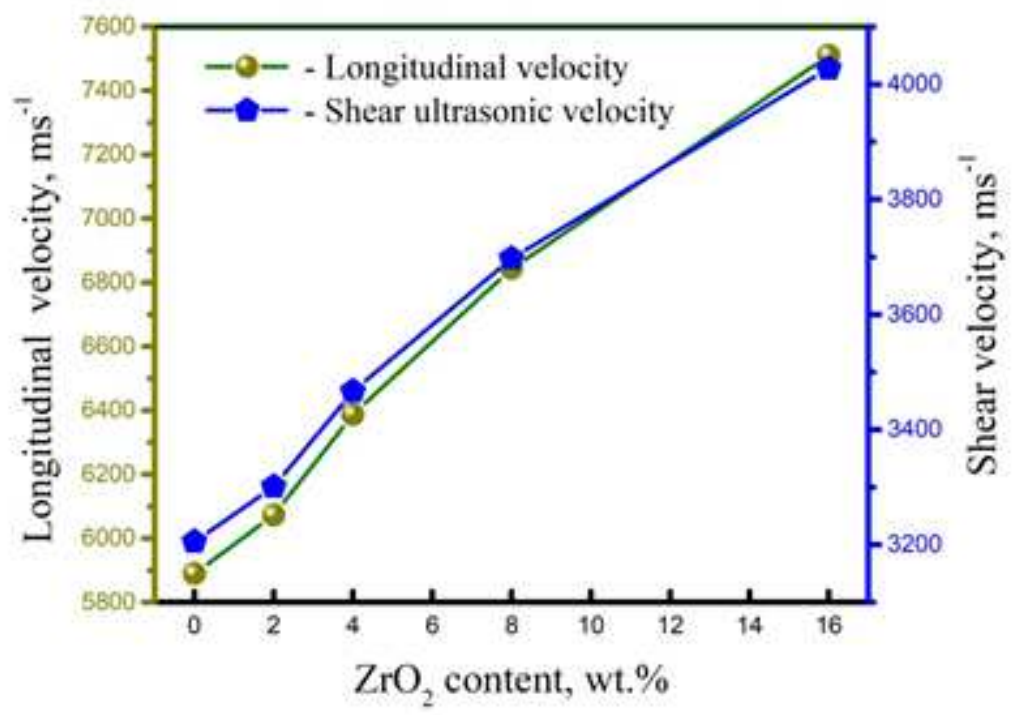

Figure 5

Ultrasonic velocities of nanocomposite samples sintered at $575{ }^{\circ} \mathrm{C}$ versus different contents of $\mathrm{VC}$ and FA.
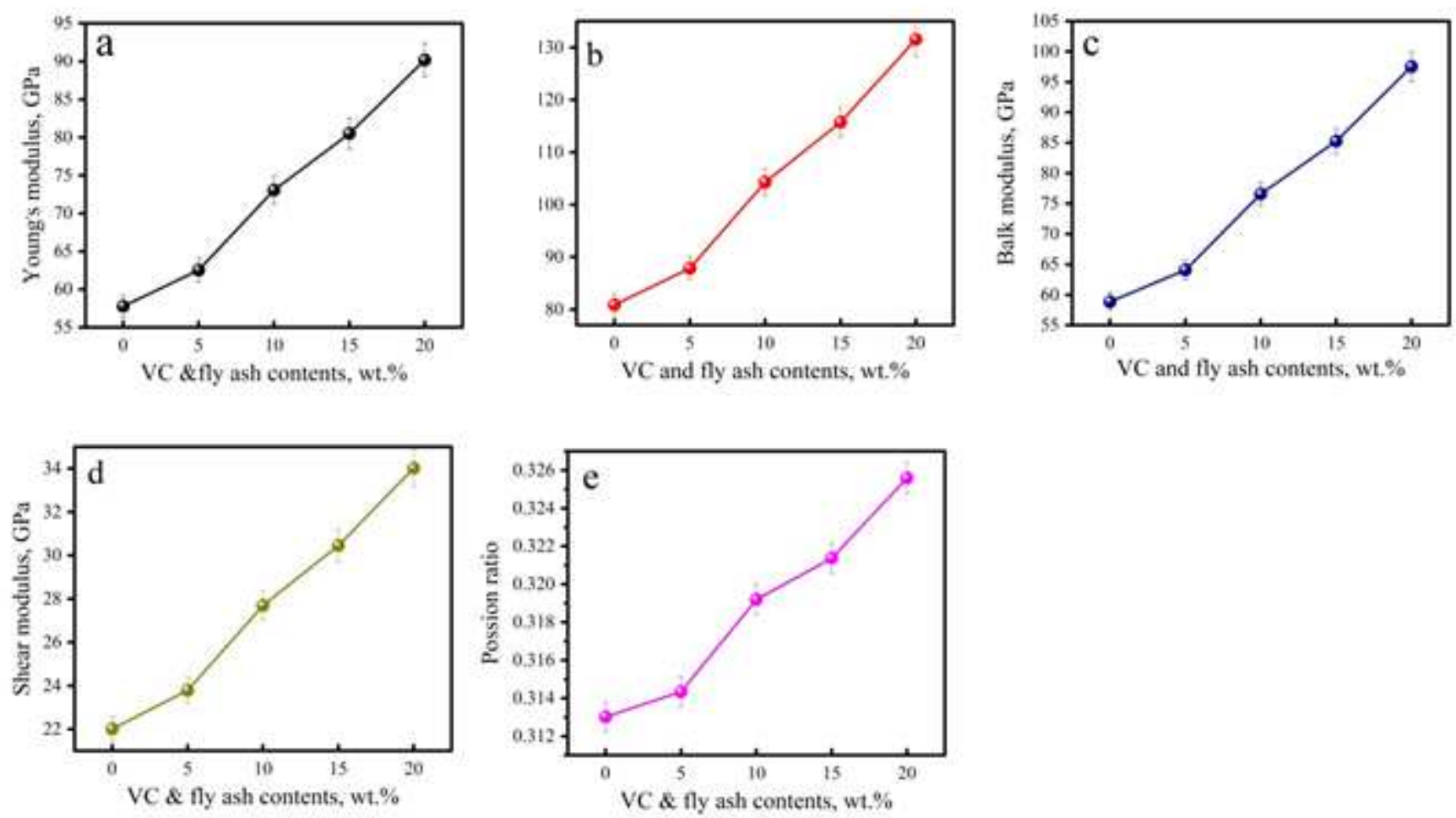

Figure 6

The group of elastic moduli of nanocomposite samples sintered at $575^{\circ} \mathrm{C}$ versus different contents of VC and FA. 


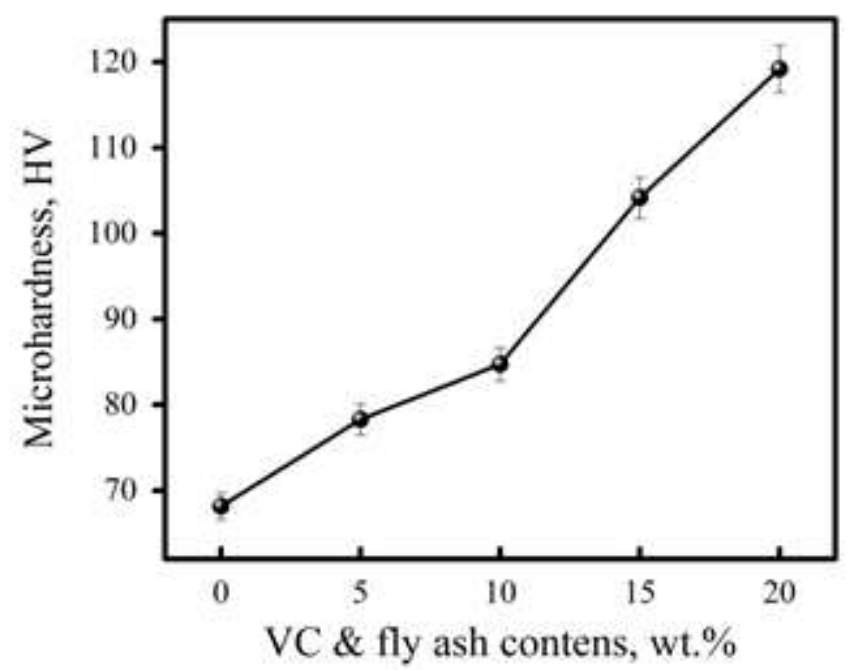

Figure 7

Microhardness of nanocomposites samples sintered at $575{ }^{\circ} \mathrm{C}$ versus VC and FA contents.

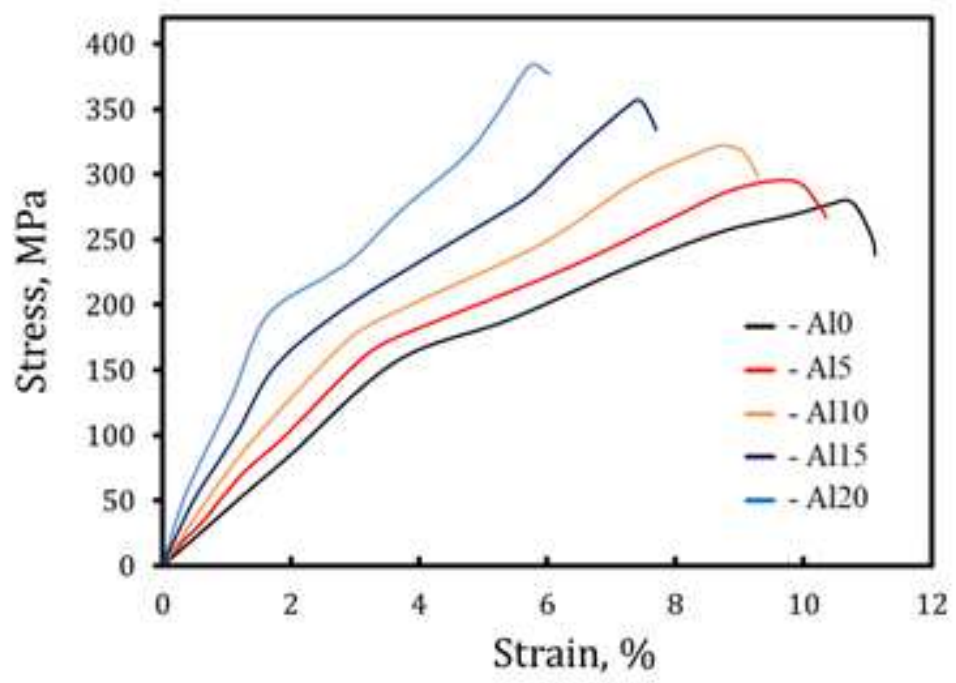

Figure 8

Compressive stress versus strain curve of Al-Si alloy/VC/FA samples sintered at $575^{\circ} \mathrm{C}$. 

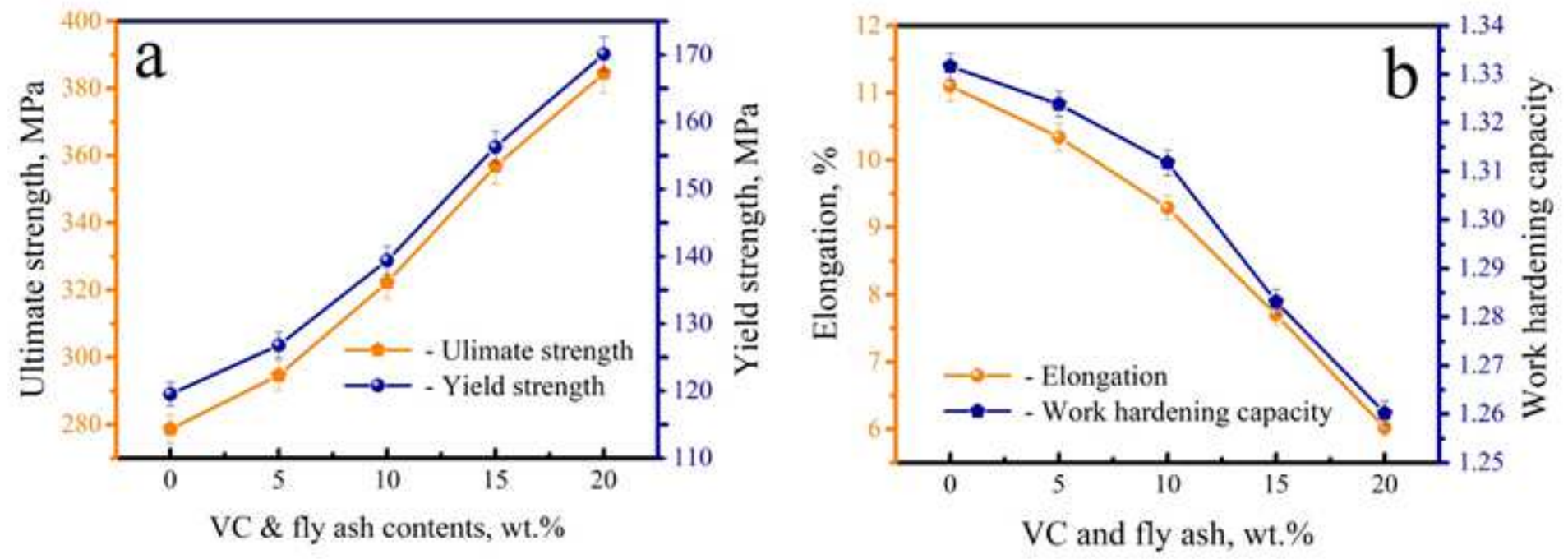

Figure 9

Ultimate compressive strength, yield strength, elongation, and work hardening capacity of sintered samples.
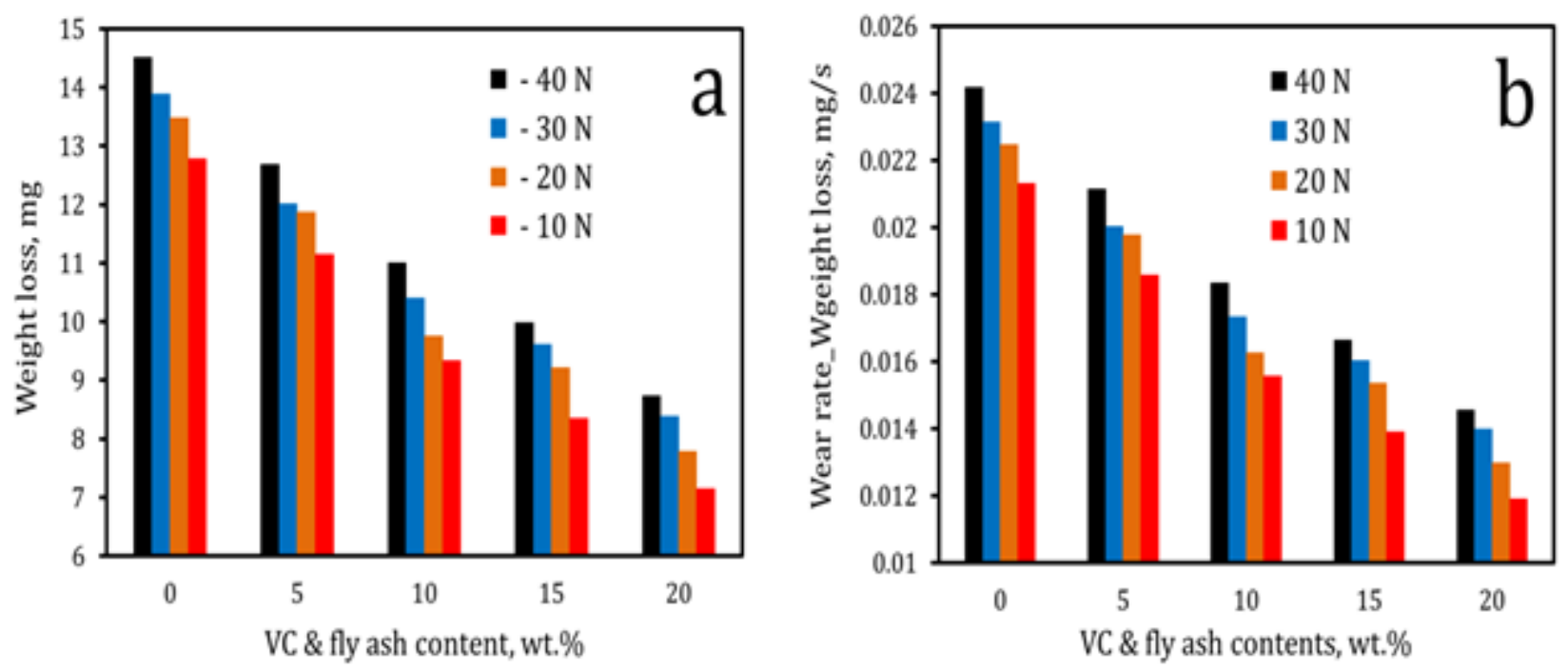

Figure 10

a) Weight loss and b) wear rate of specimens sintered at $575^{\circ} \mathrm{C}$ for different applied loads. 

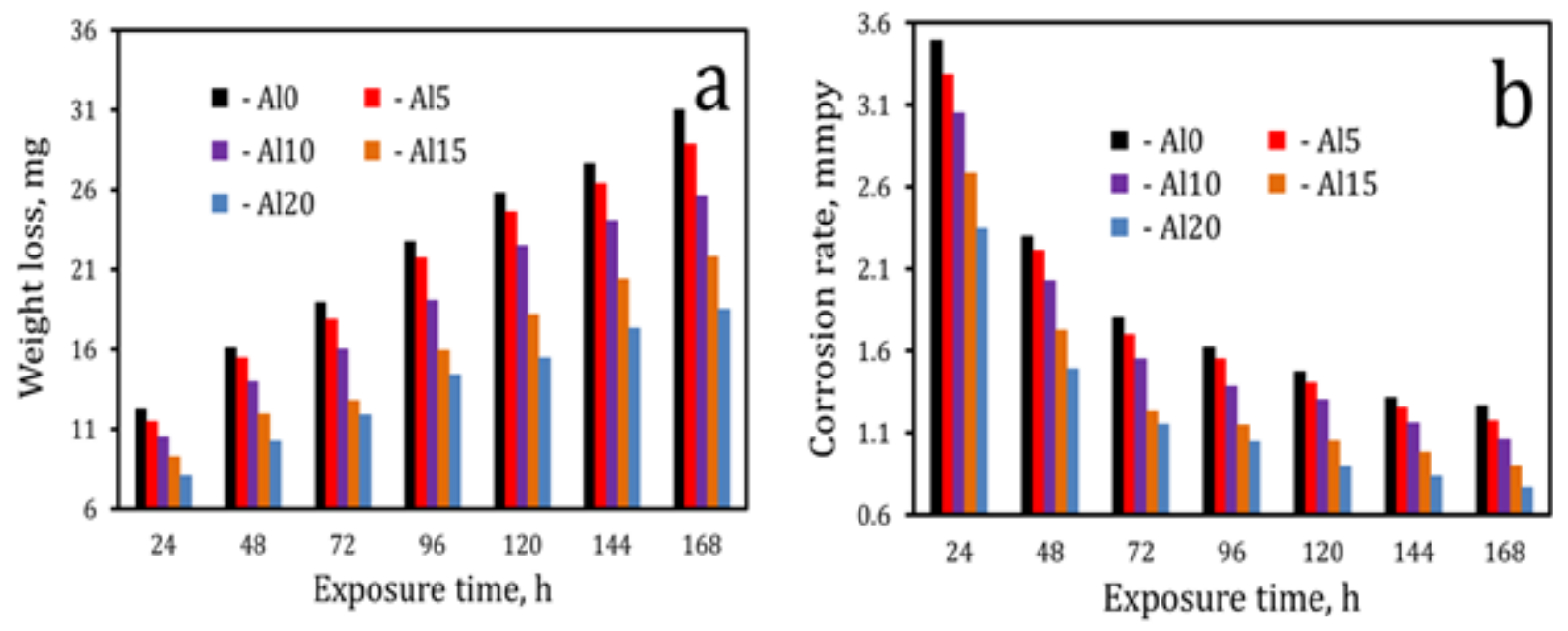

Figure 11

a) Weight loss and b) corrosion rate of specimens sintered at $575^{\circ} \mathrm{C}$ for different exposure time. 